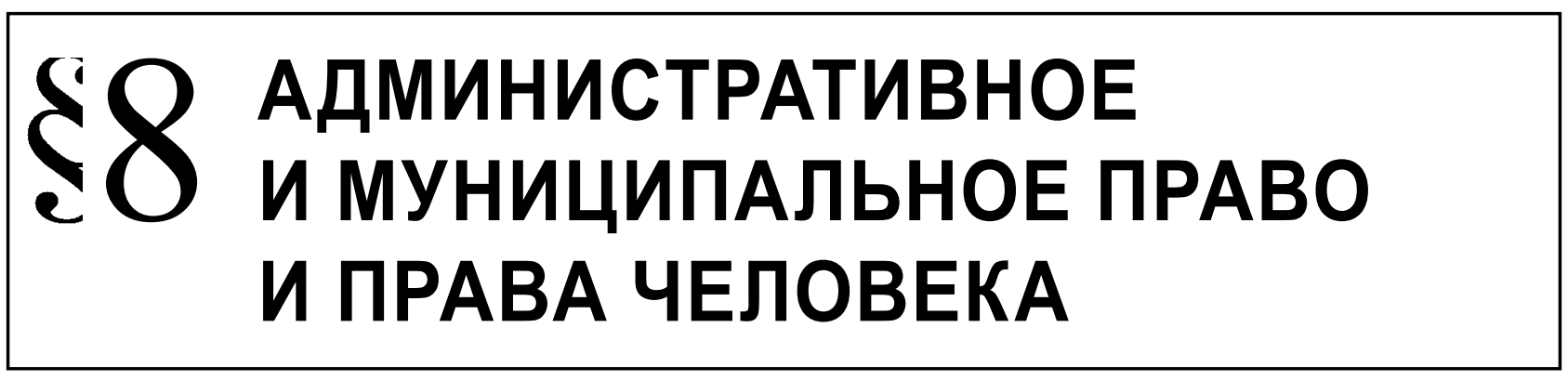

Савоськин А.B.

\title{
ДОПУСТИМО ЛИ ПРИЗНАВАТЬ РАССМОТРЕНИЕ ОБРАЩЕНИЙ ГРАЖДАН РАЗНОВИДНОСТЬЮ ГОСУДАРСТВЕННЫХ (МУНИЦИПАЛЬНЫХ) УСЛУГ?
}

\begin{abstract}
Аннотация: В статье анализируется вопрос допустимости распространения Федерального закона "Об организации предоставления государственных и муниципальных услуг» на деятельность органов публичной власти по рассмотрению обращений граждан. Изучена практика признания различными органами власти процедуры рассмотрения обращений государственной (муниципальной) услугой. Исследованы подзаконные акты, в том числе административные регламенты, определяющие рассмотрение обращений граждан в качестве государственной (муниципальной) услуги. Представлен алгоритм применения специального законодательства о государственных (муниципальных) услугах к процедуре рассмотрения обращений граждан. Публикация подготовлена на основе общенаучного диалектического метода. Специальными методами, использованными при подготовке публикации, являются: системно-структурный, формально-юридический, логический и сравнительно-правовой. В статье обоснован тезис о том, что рассмотрение обращений граждан органами власти является разновидностью государственных (муниципальных) услуг. Выявлены и проанализированы две группы административных регламентов органов власти как подтверждающие, так и опровергающие этот тезис. Предложено, первичные обращения граждан рассматривать на основании универсальных норм Федерального закона "О порядке рассмотрения обращений граждан РФ», а повторные (связанные с обжалованием ответов на первичные обращения) - по специальным правилам Федерального закона «Об организации предоставления государственных и муниципальных услуг».

Ключевые слова: обращение, право на обращение, обращения граждан, государственная услуга, муниципальная услуга, публичная услуга, административный регламент, законодательство об обращениях, жалоба, заявление.
\end{abstract}

$\Pi$ ринятие в 2010 году Федерального закона «Об организации предоставления государственных и муниципальных услуг» ${ }^{1}$ (далее Федеральный закон № 210-ФЗ) повлекло для всех органов публичной власти обязанность определить перечень реализуемых ими государственных или муниципальных услуг, а также принять административные регламенты о порядке предоставления каждой их них. В частности были приняты административные регламенты предоставления

Федеральный закон от 27.07.2010 № 210-Ф3 (ред. от 28.12.2013) «Об организации предоставления государственных и муниципальных услуг» // Собрание законодательства РФ. 02.08.2010. № 31. Ст. 4179.

такой услуги как «рассмотрение обращений граждан». Однако, в настоящий момент подобные акты имеются не во всех органах власти, а существующие - по-разному закрепляют порядок рассмотрения обращений граждан.

Некоторые административные регламенты принимались еще до внесения поправок в Федеральный закон № 210-Ф3 и не учитывают нормы о досудебном обжаловании, появившиеся в нем в декабре 2011 года² ${ }^{2}$ Другие административные регла-

\footnotetext{
Федеральный закон от 03.12.2011 № 383-Ф3 «О внесении изменений в отдельные законодательные акты Российской Федерации» // Собрание законодательства РФ. 05.12.2011. № 49 (ч. 5). Ст. 7061.
} 
менты (разработанные уже с учетом особенностей досудебного обжалования государственных или муниципальных услуг) не проводят различий между специальным и общим (универсальным) обжалованием, установленным Федеральным законом «0 порядке рассмотрения обращений граждан Российской Федерации» ${ }^{3}$ (далее Федеральный закон № 59-Ф3), то есть не фиксируют различий между Федеральным законом № 210-ФЗ и Федеральным законом № 59-Ф3.

Сложившаяся ситуация возникла по причине совпадения предмета регулирования Федерального закона № 59-ФЗ и Федерального закона № 210-ФЗ. Во-первых, процедура рассмотрения обращений граждан подпадает под нормативное определение государственной (муниципальной) услуги. Вовторых, и тот и другой закон регулируют порядок подачи и рассмотрения внесудебных жалоб.

Возникает закономерный вопрос, какой из указанных законов считать специальным, с точки зрения теории права о толковании коллизий? С одной стороны, для правового института обращений граждан Федеральный закон № 59-ФЗ является общим, а Федеральный закон № 210-ФЗ специальным, так как регулирует самостоятельную разновидность обращений - досудебные жалобы на решения и действия (бездействие) органа, предоставляющего государственную (муниципальную) услугу. С другой стороны, для правового института публичных услуг, общим является Федеральный закон № 210Ф3, поскольку Федеральный закон № 59-Ф3 регулируют лишь одну из услуг, предоставляемых государственным или муниципальным органом.

Обозначенные проблемы толкования права, в совокупности со сложностью системы законодательства об обращения, а также невысокой правовой квалификацией отдельных разработчиков подзаконных актов повлекли разнобой в содержании административных регламентов, когда одно и то же конституционное право на обращение (статья 33 Конституции РФ) в различных органах власти реализуется по-разному. Это в свою очередь повлекло нарушение единообразия в правоприменении и, например, существенно затруднило привлечение к административной ответственности должностных лиц, допустивших нарушение порядка рассмотрения обращений граждан.

\footnotetext{
3 Федеральный закон от 02.05.2006 № 59-Ф3 (ред. от 02.07.2013) «О порядке рассмотрения обращений граждан РФ» // Собрание законодательства РФ. 08.05.2006. № 19. Ст. 2060.
}

Сложившаяся ситуация грубо нарушает принципы законности и равноправия, является ярким свидетельством низкого качестве проработки вопросов связанных с нормативным регулированием порядка рассмотрения обращений граждан и должна быть исправлена. Однако, ее возникновение предопределено не только сложностью нормативного регулирования и отдельными субъективными факторами. В отечественно юридической науке на концептуальном уровне все еще не решен вопрос ${ }^{4}$, признавать ли обращения граждан разновидностью государственных и муниципальных услуг? Для того чтобы ответить на него, исследуем федеральные законы № 210-ФЗ и № 59-ФЗ подробнее.

Начать следует с нормативного определения государственной (муниципальной) услуги, представленной в пункте 1 статьи 2 Федерального закона № 210-ФЗ. Это деятельность органа власти по реализации функций государственного органа или органа местного самоуправления, осуществляемая по запросам заявителей. Исчерпывающий перечень таких услуг нормативно не определен. Порядок предоставления государственной (муниципальной) услуги устанавливается административным регламентом, однако, его отсутствие не означает отсутствия функции органа власти и не препятствует предоставлению соответствующей ей услуги. Являясь подзаконными актами, административные регламенты устанавливают состав, последовательность, сроки выполнения административных процедур и иные вопросы, связанные с предоставлением услуги, но не подменяют собой регулирование, установленное федеральными законами для каждой государственной или муниципальной услуги.

Пункт 1 «Правил разработки и утверждения административных регламентов предоставления государственных услуг» (утвержденных Правительством РФ в мае 2011 года 5 ) установил, что: «Настоящие Правила определяют порядок разработки и утверждения федеральными органами

\footnotetext{
4 Пантелеев В.Ю., Савоськин А.В. Новое в законодательстве о досудебной защите прав граждан при предоставлении государственных и муниципальных услуг // Вестник Бурятского государственного университета. 2014. - Т. 2. - № 1. C. $186-190$.

5 Постановление Правительства РФ от 16.05.2011 № 373 «О разработке и утверждении административных регламентов исполнения государственных функций и административных регламентов предоставления государственных услуг» // Собрание законодательства РФ. 30.05.2011. № 22. Ст. 3169.
} 
исполнительной власти... административных регламентов предоставления государственных услуг, в том числе по рассмотрению обращений граждан Российской Федерации в соответствии с Федеральным законом «О порядке рассмотрения обращений граждан Российской Федерации». Таким образом, высшим исполнительным органом власти в России, рассмотрение обращений граждан было признано разновидностью государственных услуг. Это повлекло повсеместное принятие административных регламентов предоставления такой услуги не только федеральными органами власти ${ }^{6}$, но и органами власти субъектов $\Phi^{7}$ и органами местного самоуправления ${ }^{8}$.

Однако, в декабре 2012 года9 из приведенного выше пункта слова «в том числе по рассмотрению обращений граждан Российской Федерации в соответствии с Федеральным законом «О порядке рассмотрения обращений граждан Российской Федерации» были исключены.

Важно подчеркнуть, что новая редакция «Правил разработки и утверждения административных регламентов предоставления государ-

6 См., например, Приказ Минэкономразвития РФ от 14.10.2011 № 569 «Об утверждении Административного регламента Федеральной службы государственной статистики по предоставлению государственной услуги по организации приема граждан, обеспечению своевременного и полного рассмотрения устных и письменных обращений граждан, принятию по ним решений и направлению ответов заявителям в установленный законодательством Российской Федерации срок» // Бюллетень нормативных актов федеральных органов исполнительной власти. 02.01.2012. № 1.

7 См., например, Приказ Министерства агропромышленного комплекса и продовольствия Свердловской области от 25.12.2012 № 423 «Об утверждении Административного регламента министерства агропромышленного комплекса и продовольствия Свердловской области по организации рассмотрения обращений граждан» // СПС КонсультантПлюс.

8 См., например, Постановление Главы городского округа Красноуфимск от 17.10.2012 № 1223 «Об утверждении Административного регламента Муниципального органа управления образованием Управление образованием городского округа Красноуфимск по предоставлению муниципальной услуги «Осуществление приема граждан, обеспечение своевременного и в полном объеме рассмотрения устных и письменных обращений граждан, принятие по ним решений и направление заявителям ответов в установленный законодательством Российской Федерации срок» // Вперед. 13.11.2012. № 139 .

9 Постановление Правительства РФ от 03.12.2012 № 1254 «О внесении изменения в пункт 1 Правил разработки и утверждения административных регламентов предоставления государственных услуг» // Собрание законодательства РФ. 10.12.2012. № 50 (ч. 6). Ст. 7070. ственных услуг» не декларирует рассмотрение обращений граждан в качестве государственной (муниципальной) услуги, но и не исключает из их числа. Вместе с тем, обстоятельства внесения поправки (сам факт удаления части нормы и отсутствие каких либо иных поправок в Постановлении Правительства РФ от 03.12.2012 № 1254) и последующая массовая отмена административных регламентов федеральными органами исполнительной власти наводит на мысль о фактическом исключении рассмотрения обращений граждан из числа государственных (муниципальных) услуг.

Опираясь на эти поправки, почти все федеральные органы власти отменили свои административные регламенты о рассмотрении обращений граждан ${ }^{10}$, хотя некоторые все же сохранили их ${ }^{11}$. Однако, обращает на себя внимание тот факт, что сохранившиеся регламенты не совершенствуются, как если бы о них просто забыли. Понять логику федеральных органов исполнительной власти не представляется возможным. Даже Министерство юстиции РФ (осуществляющее государственную регистрацию нормативных правовых актов, затрагивающих права, свободы и обязанности человека и гражданина), отменило административный регламент рассмотрения обращений граждан в

10 Приказ Минтруда России от 10.06.2013 № 249н «О признании утратившими силу некоторых нормативных правовых актов Министерства здравоохранения и социального развития Российской Федерации и Министерства труда и социальной защиты Российской Федерации» // Российская газета. № 154, 17.07.2013; Приказ ФСФР России от 18.07.2013 № 13-59/пз-н «О признании утратившим силу приказа Федеральной службы по финансовым рынкам от 30.10.2012 № 12-92/п3-н «Об утверждении Административного регламента по предоставлению Федеральной службой по финансовым рынкам государственной услуги по организации приема граждан, обеспечению своевременного и полного рассмотрения устных и письменных обращений граждан, принятию по ним решений и направлению заявителям ответов в установленный законодательством Российской Федерации срок» // Российская газета. № 187, 23.08.2013 и другие.

11 Например, Приказ Минсельхоза РФ от 27.04.2009 № 165 (ред. от 27.01.2010) «Об утверждении Административного регламента Министерства сельского хозяйства Российской Федерации по исполнению государственной функции «Организация приема граждан, обеспечение своевременного и полного рассмотрения устных и письменных обращений граждан, принятие по ним решений и направление ответов заявителям в установленный законодательством Российской Федерации срок» // Бюллетень нормативных актов федеральных органов исполнительной власти. № 41 . 12.10.2009. 
самом Министерстве ${ }^{12}$, но сохранило свой аналогичный регламент о рассмотрении обращений в подведомственной ей Федеральной службе исполнения наказаний ${ }^{13}$.

Не прояснят ситуацию и анализ подзаконных актов регионального и местного уровней власти. Особенно много административных регламентов о рассмотрении обращений граждан принято на уровне местного самоуправления, однако, и здесь появились факты их отмены ${ }^{14}$.

Итак, в настоящий момент в практике сложились два диаметрально противоположных подхода. Согласно первому - рассмотрение обращений граждан признается государственной (муниципальной) услугой, согласно второму - нет. Во втором случае никакие нормы Федерального закона № 210-Ф3 к обращениям не применяются. К сожалению, в настоящее время на федеральном уровне второй подход доминирует (даже в случае наличия соответствующего административного регламента в органе власти - о чем будет изложено ниже).

По глубокому убеждению автора статьи, подход, исключающий рассмотрение обращений граждан из числа публичных услуг не основан на законе, противоречит демократическим принципам и свидетельствует об отказе от принципов правового государства. С ним нельзя согласиться, поскольку рассмотрение обращений граждан является функцией органов власти, а потому должно признаваться разновидностью государственных (муниципальных) услуг. Вместе с тем необходимо учитывать, что, безусловно, прогрессивная идея

\footnotetext{
12 Приказ Минюста России от 14.06.2013 № 93 «О признании утратившим силу приказа Министерства юстиции Российской Федерации от 07.06.2012 № 114» // Российская газета. № 151. 12.07.2013.

13 Приказ Минюста России от 31.07.2012 № 147 «Об утверждении Административного регламента Федеральной службы исполнения наказаний по предоставлению государственной услуги по организации приема граждан, обеспечению своевременного и в полном объеме рассмотрения их устных и письменных обращений по вопросам, касающимся деятельности уголовно-исполнительной системы, принятию по ним соответствующих решений и направлению ответов в установленный законодательством Российской Федерации срок» // Российская газета. 03.10.2012. № 227.

14 Например, Постановление главы округа Муром от 13.02.2013 № 466 «О признании утратившим силу постановления администрации округа Муром от 29.06.2012 № 1961 «Об утверждении административного регламента предоставления муниципальной услуги по рассмотрению обращений граждан» // Муромский край. № 13. 26.02.2013.
}

признания рассмотрения обращений граждан разновидностью публичных услуг требует своего осмысления, тем более, что это существенно усложняет применение законодательства.

Для большей наглядности рассмотрим ситуацию на примере. Заявитель, на основании Федерального закона № 59-Ф3 обратился в орган государственной власти и не получил в 30-дневный срок ответ, после чего повторно обратился в тот же или вышестоящий орган власти с жалобой на незаконное бездействие.

Если применять первый подход (то есть признавать рассмотрение обращений граждан государственной (муниципальной) услугой), то при рассмотрении повторной жалобы необходимо применить главу 2.1 «Досудебное (внесудебное) обжалование...» Федерального закона № 210-Ф3. Соответственно к такой жалобе применяются особые требования, а срок ее рассмотрения составляет пятнадцать рабочих дней (без права продления), против традиционных тридцати дней по Федеральному закону № 59-ФЗ. Также отметим наличие специальной санкции за нарушение порядка рассмотрения досудебных жалоб на ненадлежащим образом оказанную публичную услугу - ст. 5.63 КоАП Р $\Phi^{15}$.

Если применять второй подход (то есть не признавать ответ на обращение гражданина предоставлением государственной (муниципальной) услуги), то при рассмотрении повторной жалобы необходимо использовать тот же самый Федеральный закон № 59-Ф3 (с теми же сроками и темы же санкциями за его нарушение - ст. 5.59 КоАП РФ). Что, кстати, было вполне логично до появления досудебного обжалования в Федеральном законе № 210-Ф3.

Нетрудно заметить, что в первом случае права заявителя защищены надежней, а административная ответственность должностных лиц строже.

Анализ не отмененных (действующих) административных регламентов показывает, что большинство федеральных органов исполнительной власти придерживаются именно второго подхода. Зачастую они полностью основываются на нормах Федерального закона № 59-ФЗ и никак не учитывают правил специального досудебного обжалования, установленных главой 2.1 «Досудебное (внесудебное) обжалование...» Федерального

15 Кодекс Российской Федерации об административных правонарушениях от 30.12.2001 № 195-Ф3 (ред. от 05.05.2014) // Собрание законодательства РФ. 07.01.2002. № 1 (ч. 1). Ст. 1. 
закона № 210-Ф3. Например, Административный регламент МЧС РФ игнорирует правила специального досудебного обжалования и даже в главе $\mathrm{V}$ «Досудебный (внесудебный) порядок обжалования» устанавливает срок рассмотрения таких обращений 30 дней с правом продления еще на

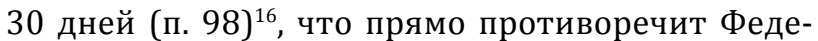
ральному закону № 210-Ф3. Аналогична ситуация в Административном регламенте Министерства сельского хозяйства $Р \Phi^{17}$ где порядок рассмотрения повторных обращений является стандартным (то есть соответствует нормам Федерального закона № 59-Ф3). Можно привести и другие аналогичные примеры.

Отрадно, что иной подход также представлен в федеральных подзаконных актах. Так, например, согласно пунктам 130 и 132 Административного регламента Министерства юстиции РФ жалобы на несогласие с полученными ответами, подписанными руководителями подразделений учреждений и органов уголовно исполнительной системы рассматриваются в течение пятнадцати рабочих дней со дня регистрации. Из иных норм регламента также следует, что к повторным жалобам применяется не Федеральный закон № 59-Ф3, а правила специального досудебного обжалования Федерального закона № 210-Ф3.

По мнению автора, признание обращений граждан разновидностью государственных (муниципальных) услуг не только соответствует Федеральному закону № 210-Ф3, но и является прогрес-

16 Приказ МЧС России от 27.09.2011 № 540 (ред. от 18.04.2012) «Об утверждении Административного регламента Министерства Российской Федерации по делам гражданской обороны, чрезвычайным ситуациям и ликвидации последствий стихийных бедствий предоставления государственной услуги по приему граждан, обеспечению своевременного и полного рассмотрения устных и письменных обращений граждан, принятию по ним решений и направлению ответов заявителям в установленный законодательством Российской Федерации срок» // Бюллетень нормативных актов федеральных органов исполнительной власти. 12.12.2011. № 50.

17 П. 5.2.1 Приказа Минсельхоза РФ от 27.04.2009 № 165 (ред. от 27.01.2010) «Об утверждении Административного регламента Министерства сельского хозяйства Российской Федерации по исполнению государственной функции «Организация приема граждан, обеспечение своевременного и полного рассмотрения устных и письменных обращений граждан, принятие по ним решений и направление ответов заявителям в установленный законодательством Российской Федерации срок» // Бюллетень нормативных актов федеральных органов исполнительной власти. 12.10.2009. № 41. сивным шагом в развитии правового института обращений граждан в России.

Во-первых, это наиболее логично, когда к первому обращению применяются универсальные нормы, а к последующему специальные, то есть происходит движение от общего к частному. Во-вторых, это повышает уровень правовой защиты, так как предполагает более жесткие требования к порядку и срокам рассмотрения повторных обращений, что особенно важно для заявителя оставшегося недовольным рассмотрением первичного обращения. В-третьих, это позволяет дополнительно дисциплинировать должностных лиц, которые несут более строгую административную ответственность за нарушение законодательства о специальных досудебных обращениях (то есть по ст. 5.63 КоАП РФ, а не по ст. 5.59 КоАП РФ) вплоть до дисквалификации.

В завершении статьи хотелось бы заявить, что автор публикации многократно проводил курсы повышения квалификации для государственных и муниципальных служащих на территории Свердловской и Тюменской областей, а также Ханты-Мансийского и Ямало-Ненецкого автономных округов и с грустью вынужден констатировать низкую правовую грамотность должностных лиц по вопросам рассмотрения обращений граждан. Несмотря на то, что административные регламенты являются подзаконными актами и не содержат положений имеющих самостоятельное значение, на практике они играют крайне важную роль. При наличии в органе власти административного регламента, служащие, рассматривая обращения граждан, на практике руководствуются именно им, а не нормами федеральных законов, поэтому от его содержания напрямую зависит эффективность внесудебной защиты субъективных прав граждан. Именно поэтому регламенты должны быть приведены в соответствие с федеральными нормами. Рассмотрение обращений должно быть окончательно признано услугой каждого государственного или муниципального органа. При этом первичные обращения должны рассматриваться на основании Федерального закона № 59-Ф3, а повторные обращения (связанные с обжалованием ответов на первичные обращения) - по правилам главы 2.1 «Досудебное (внесудебное) обжалование...» Федерального закона № 210-ФЗ. 


\section{Библиография}

1. Вестник Бурятского государственного университета. 2014. - Т. 2. - № 1. С. 186-190.

2. Васильев С.А. Проблемы развития организационно-правовых основ предоставления государственных и муниципальных услуг населению в многофункциональных центрах // Актуальные проблемы российского права. - 2013. - 12. - С. 1572-1579.

3. М.А. Липчанская Формы участия граждан в управлении делами государства в сфере исполнительной власти. // Административное и муниципальное право. - 2011. - 2. - С. 19-24.

4. П. В. Толпегин Юридическая процедура внесудебного рассмотрения обращений граждан и организаций // Право и политика. - 2012. - 9. - С. 1576-1581.

\section{References}

1. Vestnik Buryatskogo gosudarstvennogo universiteta. 2014. - T. 2 -№ 1. S. 186-190.

2. Vasil'ev S.A. Problemy razvitiya organizatsionno-pravovykh osnov predostavleniya gosudarstvennykh i munitsipal'nykh uslug naseleniyu v mnogofunktsional'nykh tsentrakh // Aktual'nye problemy rossiiskogo prava. - 2013. - 12. - C. 1572-1579.

3. M.A. Lipchanskaya Formy u chastiya grazhdan v upravlenii delami gosudarstva v sfere ispolnitel'noi vlasti. // Administrativnoe i munitsipal'noe pravo. - 2011. - 2. - C. 19-24.

4. P. V. Tolpegin Yuridicheskaya protsedura vnesudebnogo rassmotreniya obrashchenii grazhdan i organizatsii // Pravo i politika. - 2012. - 9. - C. 1576-1581. 